\title{
Prevalence, pattern, and associated psychosocial factors of headache among undergraduate students of health profession
}

\author{
Ansuman Panigrahi $^{\mathrm{a}, *}$, Basanta Kumar Behera ${ }^{\mathrm{a}}$, Nibir Nath Sarma ${ }^{\mathrm{b}}$

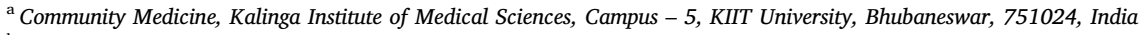 \\ ${ }^{\mathrm{b}}$ Hospital Based Cancer Registry, Gauhati Medical College, Bhangagarh, Guwahati, 781032, India
}

\section{A R T I C L E I N F O}

\section{Keywords:}

Headache

Sleep problem

Soft drink

Students of health profession

\begin{abstract}
A B S T R A C T
Background: Headache is a common health problem among health professional students which may negatively affect their academic performance and quality of life. The study aimed to determine the prevalence, pattern, associated psychosocial factors and treatment seeking behavior regarding headache among the students of health profession.

Methods: The cross sectional study was undertaken during April-September 2016 involving 339 students studying medical, dental and nursing health sciences in KIIT University, Bhubaneswar, India. A semi-structured questionnaire was used to collect all relevant information. Numeric Pain Rating Scale (NPRS) and Headache Attributed Lost Time (HALT) index were used to assess subjective perception regarding intensity of pain over the previous $24 \mathrm{~h}$ and disability burden over the last 3 months respectively.

Results: The one year prevalence of headache was $73.1 \%$, of which migraine and tension type headache were $33.3 \%$ and $19.2 \%$ respectively. In majority (93.2\%) of the students, the intensity of pain was mild to moderate. More than one third (37.1\%) of students reported that headache was affecting their family, social and leisure activities with moderate-severe impact indicating high need of medical care. Logistic regression analysis revealed that female gender (adjusted OR: 2.67), problem in falling asleep (adjusted OR: 2.86), problem in staying asleep (adjusted OR: 11.11), soft drink consumption (adjusted OR: 2.22) and self dissatisfaction with own health (adjusted OR: 1.89) were significantly associated with headache.

Conclusion: High prevalence of headache among the students of health profession necessitates designing of appropriate strategies to improve the quality of life in this population.
\end{abstract}

\section{Introduction}

Headache is considered as a common neurological disorder, ${ }^{1}$ and it is one of the main causes of morbidity that leads to workplace and school absenteeism, psychological problems, behavioral disturbances, limitation of activities of daily living and results in impaired quality of life. ${ }^{2-4}$ Headache disorders, particularly migraine, tension type and cluster headache substantially contribute to disability burden among the sufferers. ${ }^{5,6}$ It is common in all age groups with an increasing trend in the younger age groups. ${ }^{7}$ There is an increased risk of headache in individuals suffering from stress, sleeping problems; with life style habits such as smoking, coffee/soft drink consumption, family history and others. $^{5,8-11}$ Various studies have reported that the prevalence of last one year headache among students of health profession is high with a range of $46-91 \%$. $^{7,12-15}$ Deleu et al. in their study among medical students of a university in Oman observed that $96 \%$ of the students had presented at least one headache episode during the year preceding data collection. ${ }^{16}$ Frequent and severe headache negatively impacts students' academic performance which may influence their future job performance causing a huge social and economic burden on the society considering the role of health professional students in improving the community's health. ${ }^{17,18}$ Also, majority of the students suffering from headache practice self-medication leading to treatment refractoriness due to inappropriate management of their headache., ${ }^{7,19}$

Epidemiological data regarding headache in both the general population as well as specific subgroups are essential for understanding the disease frequency and distribution and planning for appropriate distribution of limited healthcare resources. ${ }^{12}$ Research in specific populations also has the advantage of helping in identification of factors influencing the frequency of headache. ${ }^{20}$ From an Indian prospective, very few studies have been done on students of health profession to evaluate the prevalence and pattern of headache. ${ }^{7,13}$ Hence our study

\footnotetext{
* Corresponding author. Community Medicine, Kalinga Institute of Medical Sciences, KIIT University Bhubaneswar, 751024, Odisha, India.

E-mail addresses: dr.ansuman3@gmail.com (A. Panigrahi), drbasantabehera@yahoo.co.in (B.K. Behera), nibir_sarma@yahoo.com (N.N. Sarma).
} 
aimed to investigate the epidemiology of headache among undergraduate students of health profession including medical, dental and nursing students studying in KIIT University in eastern India by determining the prevalence, pattern, disability burden, associated psychosocial factors and treatment seeking behavior regarding headache among the students.

\section{Materials and methods}

The present cross sectional study was undertaken in the institutes of health sciences namely Kalinga Institute of Medical Sciences (KIMS), Kalinga Institute of Dental Sciences (KIDS) and Kalinga Institute of Nursing sciences (KINS) of KIIT University, Bhubaneswar during April-September 2016. Based on the findings of a pilot study conducted in 10 students from each school, the prevalence of one year headache among the students of health profession was assumed as $70 \%$ and with absolute precision $5 \%$ at $95 \%$ confidence interval, the sample size was calculated as 323. All the students in their second to fourth year studying medical, dental and nursing science were considered eligible for the study. Each of the medical, dental, and nursing schools admits 100 students per year. Those who were unwilling to participate in the study were excluded. The circular systematic random sampling method was used to select the study population. First on the day of survey, a list of all the students present in the class was prepared. Random start point was chosen between 1 and the total number of students which was considered as the 1st study subject and then the sampling interval of 2 was added to select the other study subjects. After reaching the end of the list, it was continued from the beginning of the list thereby recruiting $50 \%$ of the students for the study. Thus, out of 810 students in three schools 405 were selected for the study and among them, 352 (86.9\%) agreed to take part as research participants. In every school, from each year, a particular theory/practical class was chosen to carry out the survey after getting permission from the concerned faculty of that class. All the student participants were invited to fill up a semi structured questionnaire to obtain relevant information. All the students were properly explained about different items in the questionnaire and their doubts were clarified before filling the questionnaire. Privacy and confidentiality were maintained during data collection. The study protocol was approved by the Institutional Ethics Committee of the author's institution (Approval number - KIMS/KIIT/ IEC/147/2015) and informed consent was sought from all the study participants prior to their inclusion in the study.

The questionnaire included three parts: First part contained socio demographic profile such as age, gender, education, life style behavior like eating habits, sleeping habit, psychological characteristics such as satisfaction with own health, satisfaction with own energy, personal relationship, financial status etc., second part included items to get information on the one year prevalence of headache, headache characteristics such as location, pattern, frequency, initiation, duration, precipitating \& ameliorating factors etc. The third part consisted Numeric Pain Rating Scale (NPRS) and Headache Attributed Lost Time (HALT) index. NPRS is an eleven point scale from 0 to $10(0=$ no pain, $10=$ most intense pain imaginable) which measures the subjective perception regarding intensity of pain over the previous $24 \mathrm{~h}$. The student participant was asked to make 3 pain ratings, corresponding to current, best and worst pain experienced over the last $24 \mathrm{~h}$ and the average of the ratings represented the student's level of pain over the past $24 \mathrm{~h} .{ }^{21}$ HALT index is a short questionnaire based on the first five questions of Migraine Disability Assessment (MIDAS) instrument used to assess the disability burden over the last 3 months. ${ }^{22}$ The questions were related to missed work days at work place, restriction of household/college work, limitation of family, social or leisure activities due to headache.

Headache was classified according to the operational diagnostic criteria of the International Headache Society (IHS). ${ }^{23}$ Two physicians trained by a consultant neurologist on the IHS diagnostic criteria further interviewed the students who had a positive history of headache to diagnose the type of headache experienced by them. Subjects having recurrent, moderate to severe unilateral throbbing headache associated with nausea or vomiting and visual disturbances were diagnosed to have migraine. The subjects with migraine were not sub classified. Subjects having bilateral or vertex tightness or pressure like feeling without gastrointestinal or visual discomfort were diagnosed to have tension type headache. The headache assessment questionnaire was validated by a consultant neurologist in an independent group of individuals suffering from migraine or tension-type headache at the neurology clinic of KIMS.

After proper cleaning and cross-checking of data, descriptive and inferential statistics were applied to analyze the data by using SPSS version 21.0 software. Simple descriptive statistical tests such as mean and standard deviation were used to describe the normally distributed continuous data; number and percentage were for the categorical data. Univariate analyses and multiple logistic regression analyses were used to identify factors associated with headache among students. The variables with $\mathrm{p}$ value $\leq 0.2$ in the Univariate analyses were entered to the multivariable model using enter regression method. Odds ratios for the association of the variables with presence of headache, with $95 \%$ confidence intervals for the odds ratios and $\mathrm{p}$ values, were estimated from logistic regression models. Using appropriate interaction terms in the multivariable model, presence of any effect modification was examined. Model fitness was checked using model chi-square statistic and Hosmer-Lemeshow goodness of fit test. $\mathrm{P}$ values $<0.05$ were regarded as statistically significant.

\section{Results}

From the total of 352 filled questionnaires, 339 (96.3\%) were filled completely and considered for analysis. Table 1 shows the demographic and psychosocial characteristics of the study participants. Mean age of the study participants was 21.33 years (SD 1.17) and majority of them were females $(222,65.5 \%)$. Of all the respondents, $37.8 \%$ were studying medical science, $34.5 \%$ nursing and rest dental science. Almost three fourth of the study participants were sleeping for more than $6 \mathrm{~h}$ per night and $43(12.7 \%)$ students were sleeping $\geq 2 \mathrm{~h}$ per day. Seventy one $(20.9 \%)$ students informed that they had problems in falling asleep and $10 \%$ had problems staying asleep. More than two third of respondents were consuming coffee/tea daily whereas one third were consuming soft drink (non alcoholic carbonated beverages) on a daily basis. Regarding quality of life, majority of students showed satisfaction with their own health, own energy, personal relationship and financial status etc.

As depicted in Table 2, 248 (73.1\%) student participants reported that they had headache in the past one year, of which $113(33.3 \%)$ had migraine, $65(19.2 \%)$ had tension type headache and the rest did not fulfill the IHS diagnostic criteria for migraine or tension type headache. All types of headache were more prevalent among females than males as female students had higher frequency of migraine $(84,74.3 \%)$ and tension type headache $(45,69.2 \%)$ than their counterparts. In majority of students (93.2\%), the intensity of pain was mild to moderate. Ninety two (37.1\%) students reported that headache was affecting their family, social and leisure activities with moderate-severe impact indicating high need of medical care.

Headache characteristics among the student participants is given in Table 3. Almost three fourth of the students complained that their headache lasted for more than 6 months. On comparison of frequency of headache, $43.5 \%$ respondents had complained headache monthly, $37.5 \%$ had this complaint on weekly basis and $19 \%$ experienced it daily. Among those who had headache complaints, $29.8 \%$ informed that they had experienced an increase in frequency of headache. It was observed that more frequent period of occurrence of headache was on weekdays and during summer season. Eighty five (34.3\%) students had sudden onset of headache, $95(38.3 \%)$ reported that their headache 
Table 1

Demographic and psycho-social characteristics among students of health profession $(\mathrm{N}=339)$.

\begin{tabular}{|c|c|}
\hline Variable & Number $(\%)$ or Mean \pm SD \\
\hline Age in years & $21.33 \pm 1.17$ \\
\hline \multicolumn{2}{|l|}{ Gender } \\
\hline Male & $117(34.5)$ \\
\hline Female & $222(65.5)$ \\
\hline \multicolumn{2}{|l|}{ Health science studying in } \\
\hline Dental & $94(27.7)$ \\
\hline Medical & $128(37.8)$ \\
\hline Nursing & $117(34.5)$ \\
\hline Number of persons staying with & $2.56 \pm 1.29$ \\
\hline Hours of sleep per night & $6.24 \pm 1.05$ \\
\hline$<6$ & $88(26.0)$ \\
\hline $6-7$ & $146(43.1)$ \\
\hline $7-8$ & $63(18.6)$ \\
\hline$>8$ & $42(12.4)$ \\
\hline \multicolumn{2}{|l|}{ Hours of sleep per day } \\
\hline Nil & $229(67.6)$ \\
\hline$<2$ & $67(19.8)$ \\
\hline$\geq 2$ & $43(12.7)$ \\
\hline \multicolumn{2}{|l|}{ Problems falling asleep } \\
\hline No & $268(79.1)$ \\
\hline Yes & $71(20.9)$ \\
\hline \multicolumn{2}{|l|}{ Problems staying asleep } \\
\hline No & $306(90.3)$ \\
\hline Yes & $33(9.7)$ \\
\hline \multicolumn{2}{|l|}{ Daily consumption of coffee/tea } \\
\hline Nil & $105(31.0)$ \\
\hline $1-2$ cups & $192(56.6)$ \\
\hline$>2$ cups & $42(12.4)$ \\
\hline \multicolumn{2}{|l|}{ Daily consumption of soft drink } \\
\hline No & $225(66.4)$ \\
\hline Yes & $114(33.6)$ \\
\hline \multicolumn{2}{|l|}{ Satisfaction with own health } \\
\hline Not satisfied & $212(62.5)$ \\
\hline Satisfied & $127(37.5)$ \\
\hline \multicolumn{2}{|c|}{ Satisfaction with own energy for everyday life } \\
\hline Not satisfied & $190(56.0)$ \\
\hline Satisfied & $149(44.0)$ \\
\hline \multicolumn{2}{|c|}{ Satisfaction with personal relationship } \\
\hline Not satisfied & $116(34.2)$ \\
\hline Satisfied & $223(65.8)$ \\
\hline \multicolumn{2}{|c|}{ Having enough money to meet personal needs } \\
\hline Not satisfied & 125 (36.9) \\
\hline Satisfied & $214(63.1)$ \\
\hline
\end{tabular}

Table 2

Headache types, intensity and headache attributed lost time among students of health profession $(\mathrm{N}=339)$.

\begin{tabular}{ll}
\hline Variable & Number (\%) \\
\hline Headache types & \\
Migraine & $113(33.3)$ \\
Tension type & $65(19.2)$ \\
Others & $70(20.6)$ \\
No headache & $91(26.8)$ \\
Intensity of pain & \\
Mild & $140(56.4)$ \\
Moderate & $91(36.7)$ \\
Severe & $17(6.8)$ \\
Headache attributed lost time grading & \\
Minimal or infrequent impact & $104(41.9)$ \\
Mild or Infrequent impact & $52(20.9)$ \\
Moderate impact & $44(17.7)$ \\
Severe impact & $48(19.4)$ \\
\hline
\end{tabular}

usually began in the evening, and $96(38.7 \%)$ affirmed that their headache reached maximal intensity within few minutes. Headache was more commonly unilateral $(35.1 \%)$ or bilateral $(30.2 \%)$ and throbbing or pulsating (58.9\%) type. Sleep disturbance (69.3\%), stress $(61.3 \%)$, and missing a meal $(41.1 \%)$ were considered as common triggering
Table 3

Headache characteristics among students of health profession $(\mathrm{N}=248)$.

\begin{tabular}{|c|c|c|}
\hline Questions & Options & Number (\%) \\
\hline \multicolumn{3}{|c|}{ Beginning of current headache since } \\
\hline & $\leq 6$ months & $68(27.4)$ \\
\hline & 6 months-1 year & $60(24.2)$ \\
\hline & $1-2$ years & $58(23.4)$ \\
\hline & $>2$ years & $62(25.0)$ \\
\hline \multicolumn{3}{|c|}{ Frequency of headaches } \\
\hline & Daily & $47(19.0)$ \\
\hline & Weekly & $93(37.5)$ \\
\hline & Monthly & $108(43.5)$ \\
\hline \multicolumn{3}{|c|}{ Increase in frequency } \\
\hline & Yes & $74(29.8)$ \\
\hline & No & $174(70.2)$ \\
\hline \multicolumn{3}{|c|}{ More frequent period of occurrence } \\
\hline & Weekdays & $75(30.2)$ \\
\hline & Weekends & $37(14.9)$ \\
\hline & Spring & $04(1.6)$ \\
\hline & Summer & $84(33.9)$ \\
\hline & Rainy & $06(2.4)$ \\
\hline & Winter & $42(16.9)$ \\
\hline \multicolumn{3}{|c|}{ Headaches typically begin } \\
\hline & Gradually & $97(39.1)$ \\
\hline & Sudden & $85(34.3)$ \\
\hline & Varies & $66(26.6)$ \\
\hline \multicolumn{3}{|c|}{ Usually begins in } \\
\hline & Morning & $38(15.3)$ \\
\hline & Afternoon & $77(31.0)$ \\
\hline & Evening & $95(38.3)$ \\
\hline & Night & $38(15.3)$ \\
\hline \multicolumn{3}{|c|}{ Reach maximal intensity } \\
\hline & Minutes & $96(38.7)$ \\
\hline & Hours & $152(61.3)$ \\
\hline \multicolumn{3}{|c|}{ Location of headache } \\
\hline & Left/Right side & $87(35.1)$ \\
\hline & Both sides & $75(30.2)$ \\
\hline & Forehead & $29(11.7)$ \\
\hline & Back of head & $16(6.4)$ \\
\hline \multicolumn{3}{|c|}{ Type of pain (Multiple responses) } \\
\hline & Throbbing/Pulsating & $146(58.9)$ \\
\hline & Tightness/Pressure & $84(33.9)$ \\
\hline & Sharp/Stabbing & $23(9.3)$ \\
\hline & Dull ache & $36(14.5)$ \\
\hline \multicolumn{3}{|c|}{ Triggering factors (Multiple responses) } \\
\hline & Stress & $152(61.3)$ \\
\hline & Sleep disturbance & $172(69.3)$ \\
\hline & Missing a meal/food related & $102(41.1)$ \\
\hline & Weather change & $67(27.0)$ \\
\hline & Noise & $74(29.8)$ \\
\hline & Bright light & $34(13.7)$ \\
\hline \multicolumn{3}{|c|}{ Alleviating factors (Multiple responses) } \\
\hline & Lying down/Sleeping & $190(76.6)$ \\
\hline & Being in a dark quit room & $95(38.3)$ \\
\hline & Massage your head & $126(50.8)$ \\
\hline & Tying something around head & $61(24.6)$ \\
\hline & Cold/hot pack on head & $10(4.0)$ \\
\hline
\end{tabular}

factors for headache among the students. Most of the student participants opined that their headache was relieved by lying down/sleeping (76.6\%), massaging head (50.8\%) and being in a dark quiet room $(38.3 \%)$

Table 4 demonstrates the factors associated with headache among student participants. Multivariable regression analysis revealed that variables such as female gender, having problem in falling asleep, problem in staying asleep, daily consumption of soft drink and dissatisfaction with own health were significantly associated with headache.

\section{Discussion}

Studying headache among University students is important as this population may be more prone to suffer headaches compared to the 
Table 4

Regression analysis of factors associated with headache among students of health profession $(\mathrm{N}=339)$.

\begin{tabular}{|c|c|c|c|c|c|c|}
\hline \multirow[t]{2}{*}{ Variables } & \multicolumn{2}{|l|}{ Headache } & \multicolumn{4}{|c|}{ OR with $95 \%$ CI } \\
\hline & No $(\%)$ & Yes $(\%)$ & COR & p value & AOR & p value* \\
\hline \multicolumn{7}{|l|}{ Gender } \\
\hline Female & $50(22.5)$ & $172(77.5)$ & 1.86 & 0.014 & 2.67 & 0.001 \\
\hline Male & $41(3.0)$ & $76(65.0)$ & & 1 & & 1 \\
\hline \multicolumn{7}{|l|}{ Department } \\
\hline Dental & $21(22.3)$ & $73(77.7)$ & 1.42 & 0.270 & & \\
\hline Medical & $36(28.1)$ & $92(71.9)$ & 1.05 & 0.871 & & \\
\hline Nursing & $34(29.1)$ & $83(70.9)$ & 1 & & & \\
\hline \multicolumn{7}{|c|}{ Number of persons staying with $(\mathrm{M} \pm \mathrm{SD})$} \\
\hline & $2.37 \pm 1.06$ & $2.63 \pm 1.36$ & 1.18 & 0.107 & 1.24 & 0.073 \\
\hline \multicolumn{7}{|c|}{ Hours of sleep per night $(M \pm S D)$} \\
\hline & $6.42 \pm 0.12$ & $6.17 \pm 0.06$ & 0.79 & 0.054 & 0.83 & 0.187 \\
\hline \multicolumn{7}{|l|}{ Problems falling asleep } \\
\hline Yes & $10(14.1)$ & $61(85.9)$ & 2.63 & 0.008 & 2.86 & 0.009 \\
\hline No & $81(30.2)$ & $187(69.8)$ & 1 & & 1 & \\
\hline \multicolumn{7}{|l|}{ Problems staying asleep } \\
\hline Yes & $01(3.0)$ & $32(97.0)$ & 13.33 & 0.011 & 11.11 & 0.019 \\
\hline No & $90(29.4)$ & $216(70.6)$ & 1 & & 1 & \\
\hline \multicolumn{7}{|c|}{ Hours of sleep per day $(M \pm S D)$} \\
\hline & $0.49 \pm 0.75$ & $0.44 \pm 0.69$ & 0.89 & 0.497 & & \\
\hline \multicolumn{7}{|c|}{ Daily consumption of coffee/tea } \\
\hline Nil & $24(22.9)$ & $81(77.1)$ & 0.79 & 0.614 & 0.72 & 0.511 \\
\hline $1-2$ cups & $59(30.7)$ & $133(69.3)$ & 0.53 & 0.134 & 0.48 & 0.107 \\
\hline$>2$ cups & $08(19.0)$ & $34(81.0)$ & 1 & & 1 & \\
\hline \multicolumn{7}{|c|}{ Daily consumption of soft drink } \\
\hline Yes & $22(19.3)$ & $92(80.7)$ & 1.85 & 0.027 & 2.22 & 0.011 \\
\hline No & $69(30.7)$ & $156(69.3)$ & 1 & & 1 & \\
\hline \multicolumn{7}{|c|}{ Satisfaction with own health } \\
\hline Not satisfied & $43(20.3)$ & 169 (79.7) & 2.38 & 0.001 & 1.89 & 0.026 \\
\hline Satisfied & $48(37.8)$ & $79(62.2)$ & 1 & & 1 & \\
\hline \multicolumn{7}{|c|}{ Satisfaction with own energy for everyday life } \\
\hline Not satisfied & $44(23.2)$ & $146(76.8)$ & 1.53 & 0.085 & 1.09 & 0.773 \\
\hline Satisfied & $47(31.5)$ & $102(68.5)$ & 1 & & 1 & \\
\hline \multicolumn{7}{|c|}{ Satisfaction with personal relationship } \\
\hline Not satisfied & $28(24.1)$ & $88(75.9)$ & 1.24 & 0.418 & & \\
\hline Satisfied & $63(28.3)$ & $160(71.7)$ & 1 & & & \\
\hline \multicolumn{7}{|c|}{ Having enough money to meet personal needs } \\
\hline Not satisfied & $36(28.8)$ & $89(71.2)$ & 0.85 & 0.535 & & \\
\hline Satisfied & $55(25.7)$ & $159(74.3)$ & 1 & & & \\
\hline
\end{tabular}

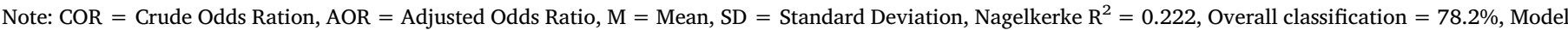
$\chi^{2} \mathrm{p}<0.001$ and Hosmer Lemeshow $\mathrm{p}=0.181$ indicates that the model adequately fits the data.

$* \mathrm{p}<0.05$ is considered as statistically significant.

general population, for reasons related to academic activities such as anxiety, stress, inadequate sleep and improper feeding habits. Similarly, students of health profession are exposed to these factors which trigger headache.

The present study revealed high prevalence of headache among students of health profession with an overall last year prevalence of $73.1 \%$. Birru et al., reported last year prevalence rate of headache as $67.2 \%$ among undergraduate medicine and health science students. ${ }^{14}$ Barros et al. reported that last year headache prevalence was $91 \%$ among medical and psychology students which is higher than our finding. ${ }^{15}$ Various studies have also shown high prevalence of headache among students of health profession with a range from $46 \%$ to 91\%. ${ }^{7,12,13,16,24}$ The discrepancy in prevalence rate might be due to variation in methodology or study population or real difference. Migraine had a higher prevalence (33.3\%) than tension type headache $(19.2 \%)$ in our study. This finding is in contrast to the results of other studies. ${ }^{12,15,24}$ Epidemiological studies have shown that the prevalence of migraine in medical students varies in the range of $6.4 \%-28.7 \%{ }^{12,24-26}$ and prevalence of tension type headache ranges from $18.1 \%$ to $59.9 \% .{ }^{12,15,24}$ The wide variation in the prevalence rates might be attributed to socio cultural, geographic, genetic and methodological differences.

We observed that most of the students described their headaches of mild to moderate intensity (93.2\%). This might be the reason for less than $10 \%$ of students with headache seeking medical attention to relieve their headache. In our study, majority of students with headache self medicated with over the counter drugs such as paracetamol, aspirin, aceclofenac, ibuprofen etc. Drugs specified for migraine or tension type headache was rarely used. Also, students reported use of various non drug headache relieving strategies like sleeping, massaging head, or resting quietly in a dark room with or without any analgesic. In an earlier study, Nandha et al. observed that headache was mild to moderate intensity in $83.1 \%$ of dental students. ${ }^{7}$ In more than one third of student participants, headache negatively impacted their academic, family, social or leisure activities indicating high need of medical care. Gowri et al. showed in their study that over $50 \%$ of medical and engineering students had headaches that had substantial to severe impact on their lives. ${ }^{27}$ However, another study conducted among health workers in South East Nigeria reported that in $13 \%$ of workers, headache had moderate to severe impact on daily activities. ${ }^{28}$

Multiple logistic regression analysis revealed that variables such as gender, sleep disorder, consumption of soft drink and self dissatisfaction with own health found to be independent predictors of headache among the student participants in our study. The likelihood of headache was 2.67 times higher among female students compared to their male counterparts. Similar result $(\mathrm{OR}=2.72, \mathrm{CI}=1.57-4.70)$ has been 
reported in another study. ${ }^{14}$ This is also consistent with several other studies. ${ }^{8,15,29}$ This difference might be due to hormonal factors, psychosocial burden on females. In this study, the older students were likely to have increased prevalence of headache as compared to younger students though it is not statistically significant. This is in agreement with reports of other studies ${ }^{14,30,31}$ which showed that the prevalence of headache rises with age. The odds of developing headache significantly increases among students who had problems in falling asleep and staying asleep than those who had not ( $\mathrm{p}<0.05)$. We also observed that students having problem in staying asleep had 11 times odds of developing headache as compared to those not complaining any problem in staying asleep. Jennum and Jensen in their clinical review of headache and sleep reported a clear association between sleep disturbance and headache. Sleep fragmentation, insomnia and hypersomnia are associated with and may cause headache. However, the mechanism and causes are complex, multifactorial and not clearly understood. ${ }^{10}$ Other studies have also documented significant association between sleep disturbance and headache disorders. ${ }^{32,33}$

In our study, medical/dental/nursing students who were consuming soft drink daily had higher likelihood of having headache compared to those not taking soft drink daily. This is in consistency with the findings of previous literatures. Kristjanson et al. observed a significant dose response relationship between soft drink consumption and headache among school children aged 10-12 years. ${ }^{34}$ In another study, Hanit et al. found that children and adolescents with daily consumption of cola drinks may suffer from daily or nearly daily headache. ${ }^{9}$ Xavier et al. also reported in their review the association of soft drink consumption and development of headache. ${ }^{35}$ The daily soft drink intake in our study participants was quite high and the present observation should serve as an alert for the institutional authorities and health providers.

Furthermore, students who were not satisfied with their own health reported headache more frequently than their counterparts. The odds of having headache increases about twice in students expressing dissatisfaction with own health compared to those who were satisfied with their own health. Lebedeva et al. showed significant association of psychological factors like depressive mood, irritability with headache among students. ${ }^{11}$ It has been widely reported that psychological factors and emotional disturbances might be associated with migraine and tension type headache. ${ }^{36,37}$ However, we did not find significant association between headache and other psychosocial factors such as personal relationship, financial status and self satisfaction with own energy for everyday life.

The study has few limitations. Being cross sectional in nature, definitive cause and effect associations cannot be established in this study. There might be recall bias as the data are based on self reporting and recalling of past experiences. Although participants in our study represent students from different corners of the country, the results of this study cannot be generalized to students of health profession from a wider geographical area as this is single centre study.

The present study revealed that headache was highly prevalent among the students of health profession and majority of the student participants did not seek medical attention and rely on simple analgesics to relieve their headache. Headache was more frequent among female students, significantly associated with life style habits such as sleep disturbance, daily soft drink consumption and one's dissatisfaction with own health. Considering all these, headache can be regarded as one of the most challenging health problem among the students of health profession. Hence, the policy makers, health professionals, academic officials and other concerned bodies should make effort in designing effective measures to curb this public health menace in this vulnerable population and thereby improving their quality of life.

\section{Funding}

This research did not receive any specific grant from funding agencies in the public, commercial, or not-for-profit sectors.

\section{Declaration of competing interest}

The authors declare that there is no conflict of interest.

\section{References}

1. Andlin-Sobockia P, Jonssonb B, Wittchenc H-U, Olesen J. Cost of disorders of the brain in Europe. Eur J Neurol. 2005;12(suppl 1) https://doi.org/10.1111/j.14681331.2005.01198.x.

2. Linde M, Dahlof C. Attitudes and burden of disease among self-considered migraineurs - a nation-wide population-based survey in Sweden. Cephalalgia. 2004;24(6):455-465. https://doi.org/10.1111/j.1468-2982.2004.00703.x.

3. Rasmussen BK, Jensen R, Olesen J. Impact of headache on sickness absence and utilisation of medical services: a Danish population study. $J$ Epidemiol Community Health. 1992;46(4):443-446. https://doi.org/10.1136/jech.46.4.443.

4. Zwart JA, Dyb G, Hagen K, et al. Depression and anxiety disorders associated with headache frequency. The Nord-Trondelag Health Study. Eur J Neurol. 2003;10(2):147-152. https://doi.org/10.1046/j.1468-1331.2003.00551.x.

5. Iliopoulos P, Damigos D, Kerezoudi E, et al. Trigger factors in primary headaches subtypes: a cross-sectional study from a tertiary centre in Greece. BMC Res Notes. 2015;8(393) https://doi.org/10.1186/s13104-015-1390-7.

6. Steiner TJ, Birbeck GL, Jensen RH, Katsarava Z, Stovner LJ, Martelletti P. Headache disorders are third cause of disability worldwide. J Headache Pain. 2015;16(58) https://doi.org/10.1186/s10194-015-0544-2.

7. Nandha R, Chhabra MK. Prevalence and clinical characteristics of headache in dental students of a tertiary care teaching dental hospital in Northern India. Int J Basic Clin Pharmacol. 2013;2(1):51-55. https://doi.org/10.5455/2319-2003.ijbcp20130110.

8. Straube A, Pfaffenrath V, Ladwig KH, et al. Prevalence of chronic migraine and medication overuse headache in Germany - the German DMKG headache study. Cephalalgia. 2010;30(2):207-213. https://doi.org/10.1111/j.1468-2982.2009. 01906.x.

9. Hering-Hanit R, Gadoth N. Caffeine-induced headache in children and adolescents. Cephalalgia. 2003;23(5):332-335. https://doi.org/10.1046/j.1468-2982.2003. 00576.x.

10. Jennum P, Jensen R. Sleep and headache. Sleep Med Rev. 2002;6(6):471-479. https://doi.org/10.1053/smrv.2001.0223.

11. Lebedeva ER, Kobzeva NR, Gilev DV, Kislyak NV, Olesen J. Psychosocial factors associated with migraine and tension-type headache in medical students. Cephalalgia. 2017;37(13):1264-1271. https://doi.org/10.1177/0333102416678389.

12. Ojini F, Okubadejo N, Danesi M. Prevalence and clinical characteristics of headache in medical students of the University of Lagos, Nigeria. Cephalalgia. 2009;29(4):472-477. https://doi.org/10.1111/j.1468-2982.2008.01766.x.

13. Bhat N, Jain S, Singh A, et al. Prevalence and characteristic of headache in dental professionals: a questionnaire based survey. $J$ Clin Diagn Res. 2016;10(4):ZC107-ZC110. https://doi.org/10.7860/JCDR/2016/17645.7699.

14. Birru EM, Abay Z, Abdelwuhab M, Basazn A, Sirak B, Teni FS. Management of headache and associated factors among undergraduate medicine and health science students of University of Gondar, North West Ethiopia. J Headache Pain. 2016;17(56) https://doi.org/10.1186/s10194-016-0647-4.

15. Ferri-de-Barros JE, Alencar MJ, Berchielli LF, Castelhano Junior LC. Headache among medical and psychology students. Arq Neuropsiquiatr. 2011;69(3):502-508. https://doi.org/10.1590/S0004-282X2011000400018.

16. Deleu D, Khan MA, Humaidan H, Al Mantheri Z, Al Hashami S. Prevalence and clinical characteristics of headache in medical students in Oman. Headache 2001;41(8):798-804. https://doi.org/10.1046/j.1526-4610.2001.01146.x.

17. Elzer AS, Elzahaf RA. Prevalence of recurrent headache among undergraduate's students of a faculty of medical technology in Derna city: a pilot study. Int J Clin Biochem Res. 2015;1(2):26-30.

18. Smitherman TA, McDermott MJ, Buchanan EM. Negative impact of episodic migraine on a university population: quality of life, functional impairment, and comorbid psychiatric symptoms. Headache. 2011;51(4):581-589. https://doi.org/10 1111/j.1526-4610.2011.01857.x.

19. Gupta R, Bhatia MS, Dahiya D, et al. Recurrent headache in Indian adolescents. Indian J Pediatr. 2009;76(7):733-737. https://doi.org/10.1007/s12098-009-0112-3.

20. Mitsikostas DD, Gatzonis S, Thomas A, Kalfakis N, Ilias A, Papageoergiou C. An epidemiological study of headaches among medical students in Athens. Headache. 1996;36:561-564.

21. McCaffery M, Beebe A. The numeric pain rating scale instructions. Pain: Clinic Manual for Nursing Practice. St.Louis: Mosby; 1989.

22. Steiner TJ, Lipton RB, Al Jumah M, et al. The Headache-Attributed Lost Time (HALT) Indices: measures of burden for clinical management and population-based research. J Headache Pain. 2018;19(12) https://doi.org/10.1186/s10194-018-0837-3.

23. Olesen J, Bendtsen L. The International classification of headache disorders, 3rd Edition (beta version). Cephalalgia. 2013;33(9):633-665. https://doi.org/10.1177/ 0333102413485658.

24. Ghorbani A, Abtahi SM, Fereidan-Esfahani M, et al. Prevalence and clinical characteristics of headache among medical students, Isfahan, Iran. J Res Med Sci. 2013;18:S24-S27 SPL. 1 http://www.scopus.com/inward/record.url?eid=2-s2.084875674813\&partnerID = 40\&md5 = bcbcfaa235e729640d13ea056958099c.

25. Balarabe S, Mufutau AY. Prevalence of migraine among medical students in Sokoto, North-Western Nigeria. Eur J Pharm Med Res. 2016;3(12):604-608. 
26. Al-Hashel JY, Ahmed SF, Alroughani R, Goadsby PJ. Migraine among medical students in Kuwait University. JThe J Headache Pain. 2014;15(26) https://doi.org/10. 1186/1129-2377-15-26.

27. Aishwarya SG, Eswari N, Chandrasekar M, Prabha JC. Prevalence and impact of primary headache disorders among students and working population in 18-25 years age group. Int J Med Res Health Sci. 2014;3(2):416-419. https://doi.org/10.5958/j. 2319-5886.3.2.084

28. Onwuekwe I, Onyeka T, Aguwa E, Ezeala-Adikaibe B, Ekenze O, Onuora E. Headache prevalence and its characterization amongst hospital workers in Enugu, South East Nigeria. Head Face Med. 2014;10(48) https://doi.org/10.1186/1746-160X-10-48.

29. Demirkirkan MK, Ellidokuz H, Boluk A. Prevalence and clinical characteristics of migraine in university students in Turkey. Tohoku J Exp Med. 2006;208(1):87-92. https://doi.org/10.1620/tjem.208.87.

30. Wang Y, Xie J, Yang F, et al. The prevalence of primary headache disorders and their associated factors among nursing staff in North China. J Headache Pain. 2015;16(4) http://doi.org/10.1186/1129-2377-16-4.

31. Straube A, Heinen F, Ebinger F, Von Kries R. Kopfschmerzen bei Schülern: prävalenz und Risikofaktoren. Dtsch Arztebl Int. 2013;110(48):811-818. https://doi.org/10. 3238/arztebl.2013.0811.

32. Yeung WF, Chung KF, Wong CY. Relationship between insomnia and headache in community-based middle-aged Hong Kong Chinese women. $J$ Headache Pain. 2010;11(3):187-195. https://doi.org/10.1007/s10194-010-0199-y.

33. Uhlig B, Engstrom M, Odegard S, Hagen K, Sand T. Headache and insomnia in population-based epidemiological studies. Cephalalgia. 2014;34(10):745-751. https:// doi.org/10.1177/0333102414540058.

34. Kristjansson AL, Sigfusdottir ID, Mann MJ, James JE. Caffeinated sugar-sweetened beverages and common physical complaints in Icelandic children aged 10-12years. Prev Med. 2014;58(1):40-44. https://doi.org/10.1016/j.ypmed.2013.10.011.

35. Xavier R, Sreeramanan S, Diwakar A, Sivagnanam G, Sethuraman KR. Soft drinks and hard facts: a health perspective. ASEAN Food J. 2007;14(2):69-81.

36. Torelli P, Abrignani G, Castellini P, Lambru G, Manzoni GC. Human psyche and headache: tension-type headache. Neurol Sci. 2008;29(SUPPL. 1):93-95. https://doi. org/10.1007/s10072-008-0896-3.

37. Zivadinov R, Willheim K, Sepic-Grahovac D, et al. Migraine and tension-type headache in Croatia: a population-based survey of precipitating factors. Cephalalgia. 2003;23(5):336-343. https://doi.org/10.1046/j.1468-2982.2003.00544.x. 